\title{
EVIDENCE OF RESTRICTED MIMETIC COLOUR POLYMOR- PHISM IN THE LARGE NARCISSUS BULB FLY, MERODON EQUESTRIS FAB. (DIPTERA : SYRPHIDAE), IN THE PYRENEES
}

\author{
D. L. T. CONN \\ Department of Zoology, University of Oxford, South Parks Road, Oxford OX1 3PS
}

Received 1.ix.75

\section{SUMMARY}

The large narcissus bulb fly, Merodon equestris, which mimics bumble bees, may be one of 34 colour types in the U.K. However in the Pyrenees individuals may be only one of 12 colour types owing to lack of variation at the bulborum gene locus. It is suggested that the simultaneous presence of other mimics in large numbers in the Pyrenees is responsible for this difference.

\section{INTRODUCTION}

The large narcissus bulb fly, Merodon equestris Fab., is one of several hover fly mimics of bumble bees. Other hover fly mimics include Volucella bombylans Linn., Criorrhina berberina Fab., C. floccosa Meig., Eristalis intricaria Linn., Arctophila bombiformis Fall. as well as Merodon flavus Sack.

In the U.K. $M$. equestris is a highly polymorphic mimic with at least 34 discernible colour types all of which are more or less mimetic. These colour types are produced by the interaction of at least six gene loci (Conn, $1971,1972 a, b)$ three of which (equestris, bulborum and ground colour) are linked and two of which depend upon the presence and modify the expression of the dominant allele of the bulborum locus (the dominant alleles of both modifier $U$ and modifier $V$ ). Three gene loci (bulborum, equestris and transversalis) were named after colour types that they produce and the other three (modifier $U$, modifier $V$ and ground colour) were named to indicate the effects that one or other of the alleles produced. Briefly, the dominant allele of bulborum blackens all but the anterior hairs of the thorax, the dominant allele of equestris blackens only an interalar band of hairs on the thorax, transversalis produces a dark band of shortened hairs on the third abdominal segment, the dominant allele of modifier $U$ modifies the colour type bulborum (produced by the dominant allele of the gene locus bulborum) to the colour type subvalidus and the dominant allele of the modifier $V$ further modifies the colour type subvalidus to the colour type validus. Both subvalidus and validus colour types show sexual dimorphism. Subvalidus males resemble bulborum males except that the second abdominal segment has a mixture of black and coloured hairs arranged in a fairly constant pattern. Subvalidus females are harder to define and more variable. The hairs of the anterior of the thorax are darkened but not black and the hair colouration of the second abdominal segment is usually similar to the male though more variable. In validus colour types the sexual dimorphism is extended further. The validus male resembles the subvalidus male except that there are now only a few isolated coloured hairs on the second abdominal segment and the validus 
female has a completely black thorax and the second abdominal segment is black except for a few isolated coloured hairs. The ground-colour locus behaves as a supergene and produces yellow and orange hairs distributed in bands (and masked whenever the dominant alleles of bulborum, equestris or transversalis are present). The colour types based on the expression of the ground-colour locus together with the recessive alleles of bulborum, equestris or transversalis are known as narcissi and may be YOYO, OOYY or OOOOthe letters referring to the yellow or orange colouration from the anterior of the thorax to the abdomen tip with the exception of the second letter which refers to the colour of the interalar band, i.e. YOYO indicates a yellow thorax, orange interalar band, yellow anterior abdomen (segment 2) and orange abdomen tip (segments 3 and 4). OOYY indicates an orange thorax (and interalar band) and an all yellow abdomen. Variants within YOYO and OOYY categories occur (YOYY, YYYO, YYYY and OOOY, OOYO) and the genetics of these has been investigated.

The colour types of $M$. equestris are generally described as narcissi YOYO, transversalis YYYO, equestris OOOO, bulborum OOOY, subvalidus YOYO, male validus OOOO, etc. As female validus are more or less completely black except for the third and fourth abdominal segments they are usually described as female validus orange tail or female validus yellow tail. In the cases of equestris, bulborum, subvalidus and male validus the orange interalar band is masked, so this inconsistency of nomenclature should be borne in mind when one considers the genetic constitution of the insects. Another inconsistency of nomenclature is to be found in male validus, as the colouration of the few light-coloured hairs on the second abdominal segment is often difficult to distinguish.

\section{Methods}

Four sites in the Pyrenees were sampled. Three were in Andorra (Vallée d'Incles at an altitude of $1800 \mathrm{~m}$, Encamp at $1350 \mathrm{~m}$ and above El Serrat at approximately $2100 \mathrm{~m}$ ) and one site was in France at Bareilles (altitude $1100 \mathrm{~m}$ ), Hautes Pyrénées. Models (bumble bee females and workers) and mimics (including bumble bee males and hover fly species) were sampled by simple netting and a total of 86 specimens of $M$. equestris were caught. Twenty museum specimens of $M$. equestris from various parts of the Pyrenees were also examined in the British Museum (Natural History) and Hope Department, Oxford collections.

\section{Results AND Discussion}

The samples of $M$. equestris taken, and the museum collections examined, all lacked individuals of the bulborum, subvalidus and validus colour types (table 1, $a$ to $e$ ). The dominant allele of the bulborum locus was absent. Furthermore, most specimens caught were equestris YOYO or equestrisransversalis YOYO. In comparison with samples from the U.K. (see Conn, $1972 b$ ) the range of colour types of $M$. equestris present in the Pyrenees is very restricted.

At the time that $M$. equestris is flying in the Pyrenees (in August) there are many other bumble bee mimics out as well. The major mimic of female and 
TABLE 1

Numbers of different morphs of $\mathrm{M}$. equestris captured at four sites in the Pyrenees (For explanation of colour types see text)

$$
\text { Colour type Males Females Total }
$$

(a) Vallée d'Incles (18-19.8.71)

$\begin{array}{llrr}\text { Equestris YOYO } & 9 & 3 & 12 \\ \text { Equestris YYYY } & 0 & 2 & 2 \\ \text { Equestris OOYY } & 1 & 0 & 1 \\ \text { Equestris-transversalis YOYO } & 1(?) & 7 & 8 \\ \text { Equestris-transversalis YYYY } & 0 & 6 & 6 \\ \text { Transversalis YYYO } & 0 & 2 & 2 \\ & - & - & -1\end{array}$

(b) Vallé d'Incles (5-9.8.73)

$\begin{array}{lccc}\text { Equestris YOYO } & 3 & 1 & 4 \\ \text { Equestris OOOO } & 1 & 0 & 1 \\ \text { Equestris transversalis YOYO } & 3(?) & 0 & 3 \\ \text { transversalis YYYO } & 1(?) & 0 & 1 \\ & - & - & -\end{array}$

(c) Encamp (7-9.8.73)

$\begin{array}{lllr}\text { Equestris YOYO } & 9 & 1 & 10 \\ \text { Equestris YYYY } & 1 & 0 & 1 \\ \text { Equestris OOYY } & 1 & 0 & 1 \\ \text { Equestris-transversalis YOYO } & 1(?) & 4 & 5 \\ \text { Equestris-transversalis OOYY } & 1(?) & 0 & 1 \\ \text { Narcissi YYYO } & 2 & 0 & 2 \\ & -15 & - & -\end{array}$

(d) Above El Serrat (6-8.8.73)

Equestris YOYO

Equestris YYYY

$\begin{array}{rrr}2 & 0 & 2 \\ 0 & 2 & 2 \\ 0 & 2 & 2 \\ 0 & 1 & 1 \\ -2 & - & -\end{array}$

Equestris-transversalis YOYO

Narcissi YYYO

(e) Bareilles (12-13.8.73)

$\begin{array}{llll}\text { Equestris YOYO } & 4 & 0 & 4 \\ \text { Equestris OOYY } & 2 & 0 & 2 \\ \text { Equestris-transversalis YOYO } & 0 & 2 & 2 \\ \text { Equestris-transversalis YYYY } & 0 & 3 & 3 \\ \text { Equestris-transversalis OOYY } & 0 & 2 & 2 \\ \text { Transversalis YYYO } & 0 & 1 & 1 \\ \text { Transversalis YYYY } & 0 & 1 & 1 \\ \text { Narcissi YYYO } & 1 & 0 & 1 \\ \text { Narcissi OOYY } & 1 & 1 & 2 \\ \text { Narcissi OOOY } & 1 & 0 & 1 \\ & - & - & -19\end{array}$


worker bumble bees is the male bumble bee (table 2, $a$ to $c$ ) and other mimics include Arctophila bombiformis, M. flavus and Volucella bombylans. $A$. bombiformis is an excellent mimic. To the human eye it is a better mimic than $M$. equestris var. bulborum, so that it is likely that bulborum colour types may be unfit at any frequency when compared with equestris, transversalis and narcissi colour types. On higher ground $M$. equestris co-exists with its sibling species $M$. flavus - of which the male resembles $M$. equestris var. narcissi and the female, $M$. equestris var. transversalis. The only other bumble bee mimic with colouration akin to that of $M$. equestris var. equestris and var. equestristransversalis is $V$. bombylans var. haemorhoidalis and this species, because of its

TABLe 2

Numbers of models and mimics caught by net sampling at three sites in the Pyrenees

Colour type in terms of $M$. equestris*

$\overbrace{n / t \quad e \quad b-t \quad b-t \quad s \text { and } v}$

(a) Vallée d'Incles (5-9.8.73)

Female and worker bumble bees (models)

Male bumble bees (mimics)

Merodon equestris

Volucella bombylans

Arctophila bombiformis

$\begin{array}{rrrrr}0 & 0 & 38 & 6 & 1 \\ 2 & 10 & 23 & 14 & 8 \\ 1 & 7 & 1 & 0 & 0 \\ - & - & 3 & 0 & 0 \\ - & - & - & 5 & -\end{array}$

(b) Encamp (7-9.8.73)

Female and worker bumble bees (models)

Male bumble bees (mimics)

Merodon equestris

Merodon flavus

(c) Above El Serrat (6-8.8.73)

Female and worker bumble bees (models)

Male bumble bees (mimics)

Merodon equestris

Merodon flavus

Volucella bombylans

$\begin{array}{rrrrr}25 & 9 & 20 & 21 & 0 \\ 4 & 3 & 5 & 3 & 0 \\ 0 & 10 & 8 & 0 & 0 \\ 1 & - & - & - & -\end{array}$

* Key: $n / t=$ narcissi/transversalis; $e=$ equestris $; e-t=$ equestris-transversalis; $b-t=$ bulborumtransversalis; $s$ and $v=$ subvalidus and validus.

larval history as a scavenger or parasite of bumble bee nests, would probably be incapable of outnumbering $M$. equestris. The above may explain the preponderance of equestris and equestris-transversalis in the samples. At Bareilles, the lowest location and well below where $M$. flavus is to be found, there is a higher proportion of non-equestris and non-equestris-transversalis colour types. It is worth noting in passing that in the Pyrenees many male $M$. equestris express transversalis, or something akin to it, rather weakly (table $1, a$ to $c$ ). In the U.K. it is very rare for any male $M$. equestris to express transversalis. The difference may be the result of the same selective forces that give rise to the high frequency of female transversalis in the Pyrenees when compared to the U.K.

The principle reason for restricted colour polymorphism of $M$. equestris 
in the Pyrenees may lie in the short summer, resulting in most other bumble bee mimics flying at the same time as $M$. equestris. The length of the season in the U.K. allows different mimics to fly at different times in the season. In the U.K., M. equestris adults are on the wing between mid-May and the end of June. They are out before most male bumble bees and before $V$. bombylans and, although $A$. bombiformis and $M$. flavus are not found in the U.K., $M$. equestris co-exists with $C$. berberina, $C$. flocosa and $E$. intricaria. However, none of these three species is every locally as common as $M$. equestris, unlike $A$. bombiformis and $M$. flavus in the Pyrenees. As one comes down the Pyrenees the summer season lengthens and it would be interesting to discover what happens to the mimicry of bumble bees and the mimetic colour polymorphism of $M$. equestris in the lower Pyrenees.

Acknowledgments.-I am extremely grateful to the staff of the British Museum (Natural History) and the Hope Department of Entomology, Oxford for allowing me to examine specimens of $M$. equestris and South European bumble bees, and to Dr I. H. M. Yarrow who suggested the Vallée d'Incles as a suitable site. I also thank Dr W. D. Hamilton for supervision, Professor T. R. E. Southwood for facilities at Imperial College Field Station, Professor J. W. S. Pringle for enabling me to complete this work and the Agricultural Research Council for the research assistantship from 1967 to 1971.

\section{ReFERENGES}

ConN, D. L. T. 1971. The genetics and biology of the large narcissus bulb fly, Merodon equestris Fab. Ph.D. Thesis, University of London.

ConN, D. L. T. 1972a. The genetics of the bee-like patterns of Merodon equestris. Heredity, 28, 379-386.

ConN, D. L. T. 1972b. The genetics of mimetic colour polymorphism in the large narcissus bulb fly, Merodon equestris Fab. (Diptera : Syrphidae). Phil. Trans. R. Soc. B, 264, 353-402. 